\title{
Determination of Forming - Limit Diagrams Considering Various Models for Steel Sheets
}

\author{
Ján Slota (SK) jan.slota@tuke.sk \\ Emil Spišák (SK) emil.spisak@tuke.sk
}

\begin{abstract}
BIOGRAPHICAL NOTES
doc. Ing. Ján Slota, PhD. (born 1974) is associated professor of Department of Technologies and Materials, Faculty of Mechanical Engineering, Technical University of Košice. He is graduated on Faculty of Mechanical Engineering, TU in Košice, where he received also scientific degree $\mathrm{PhD}$ and where he habilitated at the field of mechanical engineering processes and materials. From 2004, he has been head of section of Computer Aided of Production Engineering on the Department. His research works are mainly focused on the area of computer simulations in deep-drawing processes. He is a member of International Deep-Drawing Research Group. He is author of three university textbooks and more than 70 publications in journals and conference proceedings at Slovakia and abroad. He has been worked on several grant projects, research tasks and many projects solved for industry.

prof. Ing. Emil Spišák, CSc. (born 1955) is professor of Department of Technologies and Materials, Faculty of Mechanical Engineering, Technical University of Košice. He is head of the Department of Technologies and Materials and Vice-Rector for Development and Construction of the University. He served as Vice-Dean for 4 years and ViceRector for 8 years. He works in the area of evaluating of material properties, material failures, analysis and quantification of production factors influence in production of thin steel sheet stamping parts, modelling and simulation of technological processes, mainly forming processes. He is national secretary and a member of International Deep-Drawing Research Group. He is author of 5 monographs and more than 200 publications in journals and conference proceedings at Slovakia and abroad. His published works were cited 115 times. He has been worked on 60 grant projects, research tasks and 47 projects solved for industry.
\end{abstract}

\section{KEY WORDS}

Forming-Limit Diagrams, Prediction Models, Sheet Metal Forming

\section{ABSTRACT}

In this paper a comparative investigation of three mathematical models (Marciniak - Kuczynski model, Swift-Hill model and Sing-Rao model) as well as on an empirical model proposed by the North American Deep Drawing Research Group (NADDRG) has been carried out. The yield criterion proposed by Hill is used for the calculation of 
the limit strains in connection with the Swift's instability condition for diffuse necking and by using the Marciniak - Kuczynski analysis. The emphasis of this investigation is to consider these different approaches to predicting the FLD. Experimental results has been carried out for low carbon steel sheets of drawing quality as well as rephosphorised, TRIP and micro-alloyed steels. It was compared, which theoretical model showing good correlation with experiment, thus, which model is suitable for materials mentioned above.

\section{INTRODUCTION}

The concept of forming limit diagrams (FLDs) was introduced by Keeler (1964) and Goodwin (1968) and represents the first safety criterion for deep drawing operations. Marciniak and Kuczynski (MK) have proposed a mathematical model for the theoretical determination of FLDs that suppose an infinite sheet metal to contain a region of local imperfection where heterogeneous plastic flow develops and localizes. The implementation of different yield criteria in the M-K model has been investigated by several authors [1,2]. Because of the complexity of the experimental determination of the FLD, a number of theoretical calculating models have been set up on the basis of the classical or modified Swift and Hill instability criteria $[3,4]$. In recent years, the knowledge and principles of damage mechanics, plastic mechanics of porous materials, and microscopic materials science combined with the finite-element method (FEM) have also been introduced into the theoretical predictions of the FLD $[5,6,7]$. These results have significantly enriched and improved the understanding and application of the FLD. However, there has not been a general model that can be applied for various steel sheets until now and, furthermore, the still-too-complex calculations for predicting the FLD will limit their use in practical applications.

This investigation was carried out for a better understanding of the forming behaviour of selected steel sheets by means of the experimental determination and theoretical predication of the FLD.

\subsection{The Marciniak-Kuczynski model}

\section{Theoretical FLC Models}

One of the most accurate models for predicting the failure strains during biaxial stretching of thin sheets is the M-K model. However, this accuracy requires a considerable number of arithmetic operations and if the $\mathrm{M}-\mathrm{K}$ model is used in finite element method codes to guard against the failure strains, leading to a significant increase of the simulation time. The M-K model assumes that the strain localization appears in the region of a material or geometrical inhomogeneity. The initial groove or trough is assumed develop when proportional loading is applied outside the groove. The force equilibrium ensures that the strain level within the groove will grow faster than the strain outside, until eventually a plane strain condition is reached with in the groove [8]. At this point, the material is assumed to lose its capability for carrying additional load, and localized necking occurs. The M-K method has been used widely in predicting forming limits of sheet metals (e.g., $[9,10,11])$.

The model presented in this paper assumes the existence of a geometric non-homogeneity in the form of notch (zone b) perpendicular to the direction of the maximum principal stress $\sigma_{1}$. The initial thickness of the sheet metal $\mathrm{t}^{\mathrm{a}}{ }_{0}$ is greater than the initial thickness in the region which contains an imperfection $t^{\mathrm{b}}{ }_{0}$ (see Fig. 1). The sheet-metal is stretched by the principal stresses $\sigma_{1}$ and $\sigma_{2}$. The current value of the inhomogeneity coefficient (Eq. 1) is expressed by the relationship:

$f_{0}=\left(\frac{t_{b}}{t_{a}}\right)$

where $t_{a}$ and $t_{b}$ are the current values of the thickness in the regions $\mathrm{a}$ and $\mathrm{b}$, respectively.

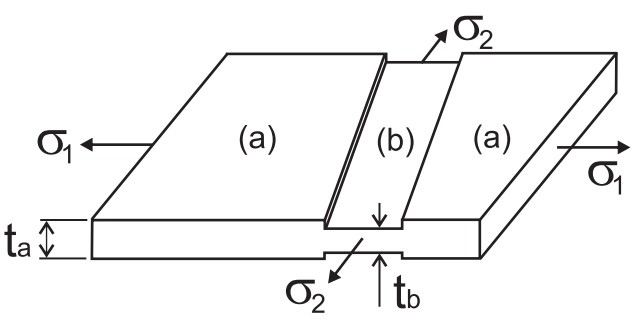

Fig. 1 Schematic of the M-K model on prediction of FLD

For each of the two regions of the sheet following the Levy-Mises equations and Hollomon's equation, respectively, are valid.

The model is completed with two equations the link between regions a and b. Equation (2) express ing the equilibrium of the along the interface of the two regions: 


$$
\sigma_{1 a} \cdot t_{a}=\sigma_{1 b} \cdot t_{b}
$$

Equation (3) expressing the fact that the strains parallel to the notch are equal in both regions

$$
d \varepsilon_{2 a}=d \varepsilon_{2 b}
$$

\subsection{The Swift-Hill model}

Swift and Hill based their analyses on the maximum force principle: the sheet metal fails when the applied force begins to decrease, that is, at failure the force reaches its maximum. When coupled with other assumption upon the deformation process, this principle can lead to an analytic expression for the particular case of proportional loading. It has been proven that a good simulation of the forming limit strains can be given on the basis of the Swift diffuse instability theory and the Hill localized instability theory $[12,13]$, and where Swift's and Hill's theories are used to calculate the forming limit strains on the left according to eq. (4) and (5) and the right side (eq. (6) and (7)), respectively, of the FLD. Assuming that the stress-strain relationship of sheets can be expressed by Hollomon's equation.

According to Swift's and Hill's criterion, the formulae calculating the forming-limit strains can be written as follows, with $\alpha=\sigma_{2} / \sigma_{1}$

afor $\varepsilon_{2}<0$

$$
\varepsilon_{1}=\frac{1+(1-\alpha) r_{m}}{1+\alpha} n
$$

afor $\varepsilon_{2}>0$

$$
\varepsilon_{2}=\frac{\alpha-(1-\alpha) r_{m}}{1+\alpha} n
$$

$$
\begin{gathered}
\varepsilon_{1}=\frac{\left[1+r_{m}(1-\alpha)\right] \cdot\left[1-\frac{2 r_{m}}{1+r} \alpha+\alpha^{2}\right]}{(1+\alpha)\left(1+r_{m}\right)\left[1-\frac{1+4 r_{m}+2 r_{m}^{2}}{(1+r)^{2}} \alpha+\alpha^{2}\right]} n \\
\varepsilon_{2}=\frac{\left[\left(1+r_{m}\right) \alpha-r_{m}\right] \cdot\left[1-\frac{2 r_{m}}{1+r} \alpha+\alpha^{2}\right]}{(1+\alpha)\left(1+r_{m}\right)\left[1-\frac{1+4 r_{m}+2 r_{m}^{2}}{(1+r)^{2}} \alpha+\alpha^{2}\right]} n
\end{gathered}
$$

\subsection{The SING-RA0 model}

According to the original Sing-Rao proposition the forming limit stress curve FLSC could be obtained using the linear regression technique based on the results of calculation using below mentioned scheme taking into account mean plastic anisotropy ratio $[14,15]$.

On the base of flow rule the surface limit strains (eq. (8) and (9)) for different stress (or strain) ratio (eq. 10) could be calculated as:

$\varepsilon_{1}=\left[\left(1+2 r_{m}\right)\left(\sigma_{1}-\sigma_{2}\right)+\left(\sigma_{1}+\sigma_{2}\right)\right] \lambda$

$\varepsilon_{2}=\left[-\left(1+2 r_{m}\right)\left(\sigma_{1}-\sigma_{2}\right)+\left(\sigma_{1}+\sigma_{2}\right)\right] \lambda$

where

$\lambda=\frac{\varepsilon_{e}}{2\left(1+r_{m}\right) \sigma_{e}}$

\subsection{The NADDRG model}

For simplifying the experimental and theoretical determination of the FLD and utilizing the FLD more easily in the press workshop, the North American Deep Drawing Research Group (NADRG) introduced an empirical equation for predicting the FLD in practise. [16] According to this model, the FLD is composed of two lines through the point $\boldsymbol{\varepsilon}_{10}$ in the plane-strain state. The slopes of the lines located on the left and right side of FLD respectively are about $45^{\circ}$ and $20^{\circ}$. The equation for calculation the forming limit strain $\boldsymbol{\varepsilon}_{10}$ in term of engineering strain can be expressed as:

$\varepsilon_{10}=\frac{\left(23,3+14,13 t_{0}\right) n}{0,21}$

where $\mathrm{t}_{0}$ is the sheet thickness in $\mathrm{mm}$ and $\mathrm{n}$ is strain hardening exponent.

\section{Experimental Work}

The materials used in the present investigation are listed in Tab. 1 along with their mechanical properties, thickness and flow curve parameters applied in the theoretical calculations of FLDs. The DX 53D is low carbon deep drawable steel sheet. ZStE $220 \mathrm{P}$ is the rephosphorised drawing quality steel that exhibits a capacity for a significant increase in strength through work hardening during 


\begin{tabular}{|l|c|c|c|c|c|c|c|}
\hline \multicolumn{1}{|c}{ Steel } & $\begin{array}{c}\text { Thickness } \\
\text { [mm] }\end{array}$ & $\begin{array}{c}\text { YS } \\
\text { [MPa] }\end{array}$ & $\begin{array}{c}\text { UTS } \\
\text { [MPa] }\end{array}$ & $\begin{array}{c}\mathbf{A}_{\mathbf{8 0}} \\
{[\%]}\end{array}$ & $\mathbf{r}_{\mathbf{m}}$ & $\mathbf{n}$ & $\mathbf{A g}$ \\
\hline DX 53D+Z & 1,0 & 232 & 324 & 36,7 & 1,515 & 0,154 & 15,0 \\
\hline ZStE 220 P & 0,8 & 234 & 380 & 34,2 & 1,676 & 0,197 & 20,4 \\
\hline QStE 340 TM & 1,25 & 386 & 483 & 25,6 & 1,076 & 0,165 & - \\
\hline TRIP & 0,75 & 444 & 766 & 26,3 & 0,816 & 0,29 & 24,0 \\
\hline
\end{tabular}

Tab. 1 Mechanical properties, thickness and flow curve parameters of the materials

\begin{tabular}{|l|c|c|c|c|c|c|c|c|c|c|c|}
\multicolumn{1}{r}{ Steel } & \multicolumn{1}{c}{$\mathbf{C}$} & Mn & $\mathbf{P}$ & $\mathbf{S}$ & $\mathbf{T i}$ & $\mathbf{S i}$ & $\mathbf{A l}$ & $\mathbf{C r}$ & Ni & Nb & Mo \\
\hline DX 53D+Z & 0,04 & 0,2 & 0,015 & 0,012 & - & 0,01 & 0,03 & - & - & - & - \\
\hline ZStE 220 P & 0,06 & 0,7 & 0,08 & 0,03 & - & 0,03 & 0,02 & - & - & - & - \\
\hline QStE 340 TM & 0,12 & 1,3 & 0,025 & 0,01 & 0,10 & - & 0,015 & - & - & 0,08 & 0,06 \\
\hline TRIP & 0,2 & 1,68 & 0,018 & 0,003 & 0,009 & 0,2 & 1,73 & 0,055 & 0,018 & 0,004 & 0,008 \\
\hline
\end{tabular}

Tab. 2 Chemical composition of the material studied (mass \%)

part formation. The QStE 340TM is high-strength low alloy steel (HSLA) for cold-forming, thermomechanically-rolled. The steel with transformation induced plasticity (TRIP) RAK 40/70 have been investigated too.

All steel sheets have been hot dip galvanised with $100 \mathrm{~g} / \mathrm{m}^{2}$ on both sides. All of the steels are produced industrially. The chemical composition of the different steel is given in Tab. 2 .

The experiments determining the FLDs for all the sheets studied have been carried out in an Erichsen 145-60 universal materials testing machine with specimens of different width and shape. Specimens were deformed by a rigid punch with hemispherical shape. The limit strains have been determined from a circular grid pattern. The flow curves have been determined by means of the conventional tensile test. In this investigation, all tests were carried out at room temperature.

\section{Results and Discussion}

Comparison between the theoretical and experimental FLDs

A comparison among the experimental forminglimit curves for steel sheets of drawing quality, rephosphorised steel, high-strength low alloy steel and TRIP steel is shown in Fig. 2. The limit strains in the plane-strain state and the nearby region for TRIP, ZStE $220 \mathrm{P}$ and QStE 340TM steels are much lower than for DX53D steel, which may be associated with its higher strength and different thicknesses of sheets, respectively. However, TRIP steel shows comparable formability in the stretch- ing region with higher strain and extremely higher limit strains in the drawing region with higher strain. Fig. 1 also shows the extreme differences among sheets in strain path, which may contribute to differences in forming behavior.

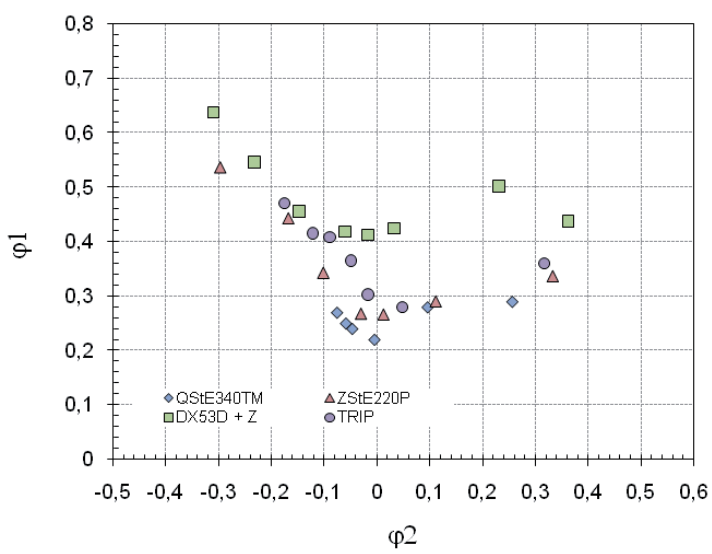

Fig. 2 The experimental forming-limit diagram of materials studied

Figs. 3, 4, 5 and 6 show the comparisons between the theoretical predictions based on the different models mentioned above and the experimental FLDs, for all the steel sheets studied. Generally speaking, there exists no one model that can beused for every material. Because of adequacy examination, the FLDs obtained by predicted mathematical models have been necessary compared with experiment. 


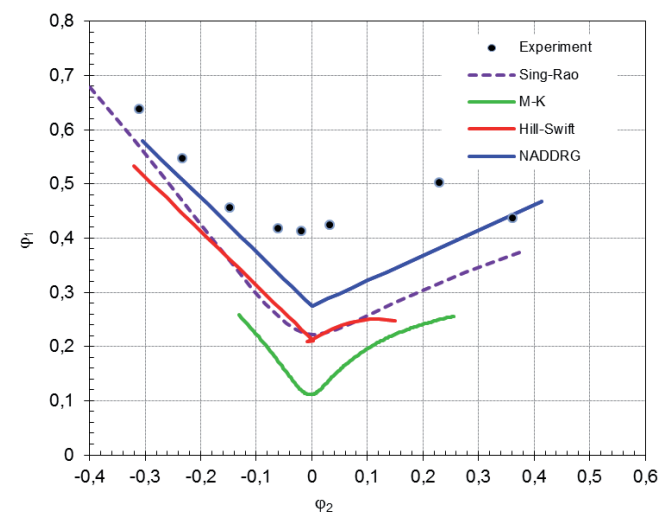

Fig. 3 The theoretical and experimental FLD for DX 53D

The simple empirical model developed by NADDRG no gives very good predications of the FLDs for all studied steels which belong to the groups of deep-drawable or high strength steel. For DX 53D this model has lower boundary of the FLDS and for ZStE 220P, QStE 340TM and TRIP steel just upper boundary than those experimental results.

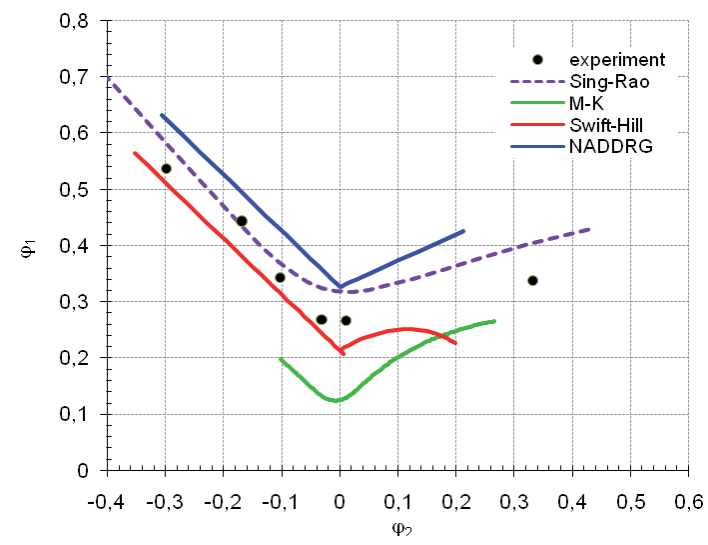

Fig. 4 The theoretical and experimental FLD for ZStE 220P

The predictions by the Hill-Swift model based on Hollomon's equation seem to give a lower boundary of the FLDs for DX 53D. The FLD calculated according to method proposed by Hill and Swift seemed to be in good correlation with experimental results only on left-hand side for ZStE 220P and TRIP. The right-hand side is much lower against experiment. This prediction seems to be able for micro-alloyed steel QStE $340 \mathrm{TM}$.

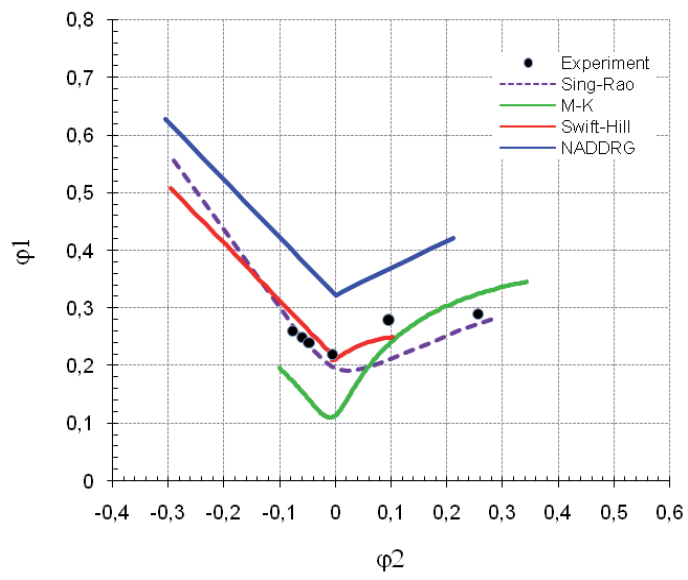

Fig. 5 The theoretical and experimental FLD for QStE 340TM

The method proposed by Sing and Rao seems to be in good correlation with experimental results for QStE 340TM. However, for materials such DX 53D, TRIP and ZStE 220P, the predictions by this model have slightly lower and upper boundaries respectively, than experiment.

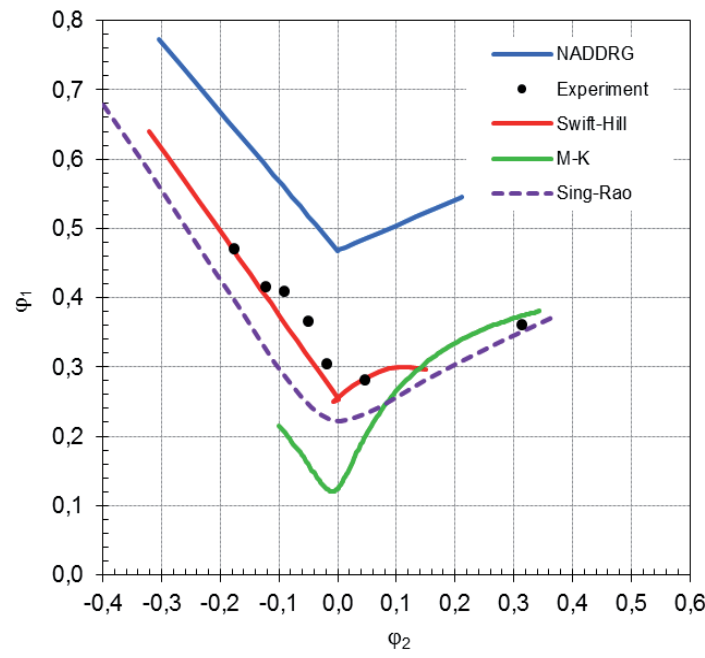

Fig. 6 The theoretical and experimental FLD for TRIP

The worst correlation between calculated and experimental results was obtained in the case of calculation according to Marciniak-Kuczynski method. The predictions by this model do not show a good coincidence with the experimental results. The predicted FLD are much lower than the measured values. Only in case of the ZStE 220P steel and the QStE 340TM steel was a satisfactory agreement 
with the experimental FLDs observed, at greater deformations in biaxial stretching especially.

Figs. 3 - 6 shows the major limit strains based on $\mathrm{M}-\mathrm{K}$ method increase rapidly and monotonically from the plane-strain state up to the equi-biaxial stress state, whereas the major limit strains based on the Hill-Swift method increase somewhat slowly and finally decrease near to equi-biaxial stress state.

The major difference between models lies in the applied strain-hardening models for material. It is obvious that the theoretical FLDs differ greatly with the strain-hardening model, and for same model the predicted accuracy varies with different materials. On the other hand, although the flow rule can represent very well the stress-strain relationships in uniaxial tension materials, the theoretical predictions still show large deviations from the experimental FLDs. This implies that an appropriate calculating method depends only on the understanding of the flow behaviour of materials, but also on the assumptions for instability criteria and perhaps on further material properties and experimental factors.

\section{Conclusion}

In this paper a comparative investigation of three mathematical models (Marciniak-Kuczynski model, Hill-Swift model, Sing-Rao model) as well as on an empirical model proposed by the North American Deep Drawing Research Group (NADDRG) and experimental results has been carried out for different steel sheets.

None of the models can predict the forming-limit diagram reliably. The FLD 0 value is met by the empirical NADDRG model and the modified SwiftHill model with sufficient accuracy for ferritic steels. The classical Swift-Hill and M-K models deliver too-small FLD 0 values. The method proposed by Sing and Rao seems to be in good correlation with experimental results for some steel sheets.

The forming-limit diagram is affected by the thickness, the yield and tensile strength, and the strain hardening and plastic anisotropy. In order to understand the influence of the material properties and make effective use of the materials, there is a need for adopting mathematical models for analysis the interacting factors as a whole, with due consideration to the practical manufacturing process constrains. Based on the formability prediction models, the analytical influence of the basic material properties have been investigated, and have been compared with experimental data.

\section{Acknowledgement}

This paper is the result of the project implementation: Center of research of control of technical, environmental and human risks for permanent development of production and production and products in mechanical engineering (ITMS:26220120060) supported by the Research \& Development Operational Programme funded by the ERDF.

\section{References}

[1] Barlat, F., Lian, J. (1989). Plastic behavior and stretchability of sheet metals. Part I. A yield function for orthotropic sheets under plane stress condition. Int. J. Plasticity, vol. 5, pp. 5166

[2] Banabic, D. (1996). Forming limit diagrams predicted by using the New Hill's criterion. Proceedings of the Numisheet '96, pp. 240-245

[3] Banabic, D., Dannenmann, E. (2001) Prediction of influence of yield locus on the limit strain in sheet metals. Journal of mat. Porc. Technology, vol. 109, pp. 9-12

[4] Djavanroodi, F., Derogar, A. (2010). Experimental and numerical evaluation of forming limit diagram for Ti6Al4V titanium and Al6061-T6 aluminum alloys sheets. Materials \& Design, vol. 31, pp. 4866-4875

[5] Ganjiani, M., Assempour, A. (2007). An improved analytical approach for determination of forming limit diagrams considering the effects of yield functions. Journal of Materials Processing Technology, vol. 182, no. 1-3, pp. 598-607

[6] Ganjiani, M., Assempour, A. (2008). Implementation of a robust algorithm for prediction of forming limit diagrams. Journal of Materials Engineering and Performance, vol. 17, no. 1, pp. 1-6

[7] Korhonen, A.S., Manninen, T. (2008). Forming and fracture limits of austenitic stainless steel sheets. Materials Science and Engineering AStructural Materials Properties Microstructure and Processing, vol. 488, no. 1-2, pp. 157-166

[8] Sowerby, R., Duncan, J.L. (1971). Failure in sheet metal in biaxial tension. Int. J. Mech. Sci., 
vol. 30, pp. 217-229

[9] Eyckens, P., Van Bael, A., Van Houtte, P. (2009). Marciniak-Kuczynski type modelling of the effect of Through-Thickness Shear on the forming limits of sheet metal. International Journal of Plasticity, vol. 25, no. 12, pp. 2249-2268

[10] Evangelista, S.H., Lirani, J., Al-Qureshi, H.A. (2002). Implementing a modified MarciniakKuczynski model using the finite element method for the simulation of sheet metal deep drawing. Journal of Materials Processing Technology, vol. 130-131, pp. 135-144

[11] Banabic, D., Comsa, S., Jurco, P., Cosovici, G., Paraianu, L., Julean, D. (2004). FLD theoretical model using a new anisotropic yield criterion. Journal of Materials Processing Technology, vol. 157-158, pp. 23-27

[12] Wang, L., Lee, T.C. (2006). The effect of yield criteria on the forming limit curve prediction and the deep drawing process simulation.International Journal of Machine Tools and Manufacture, vol. 46, no. 9, pp. 988-995.

[13] Rees, D.W.A., Power, R.K. (1994). Forming limits in a clad steel. J. Mater. Process. Technol., vol. 45, pp. 571-575

[14] Sing, W.M., Rao, K.P. (1997). Role of strain-hardening laws in the prediction of forming limit curves. Journal of Materials Processing Technology, vol. 63, no. 1-3, pp. 105-110

[15] Frącz W., Stachowicz F.: Determination of the forming limit diagram by Sing-Rao method, Acta Mechanica Slovaca, 3 (1999), str. 35-40

[16] Levy, S.B.: A comparison of empirical forming limit curves for low carbon steel with theoretical forming limit curves of Ramaekers and Bongaerts, IDDRG WG3, Ungarn, (1996)

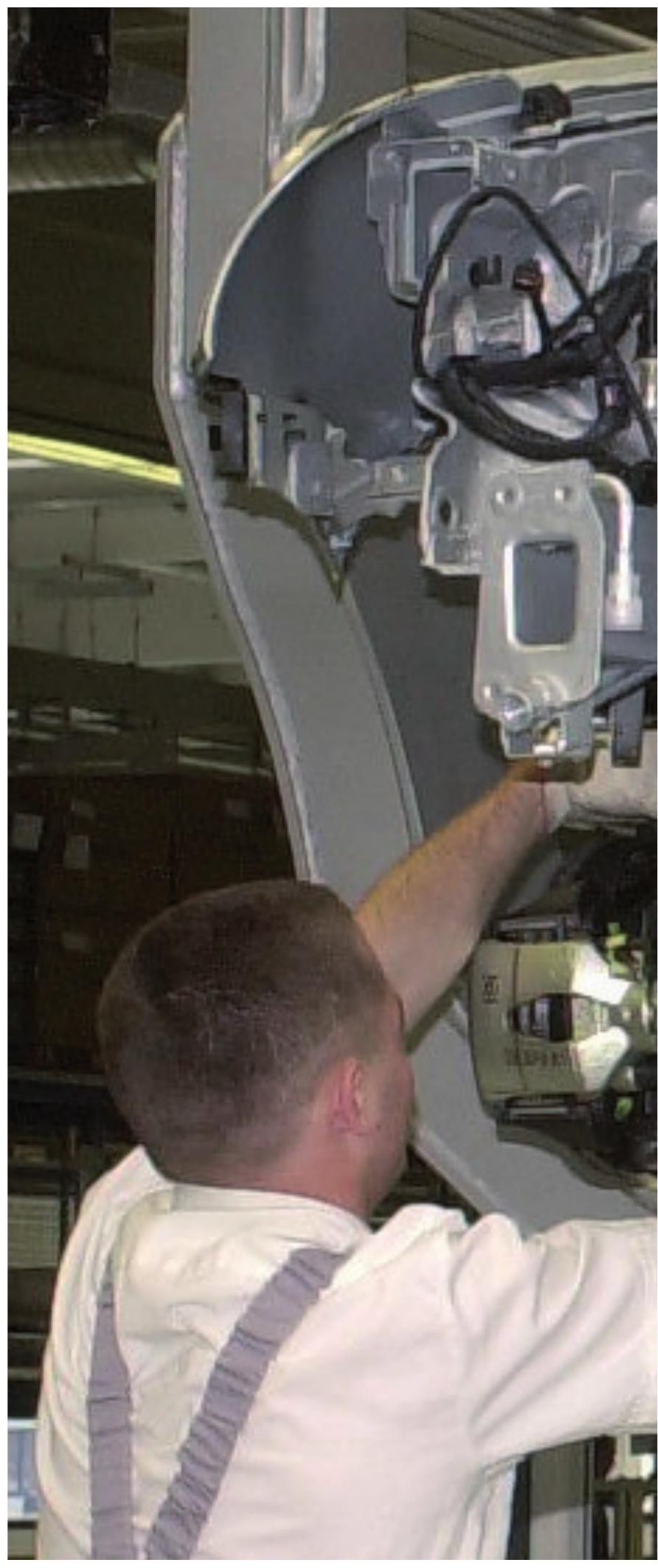

